\title{
Positive behaviour support in South African Foundation Phase classrooms: Teacher reflections
}

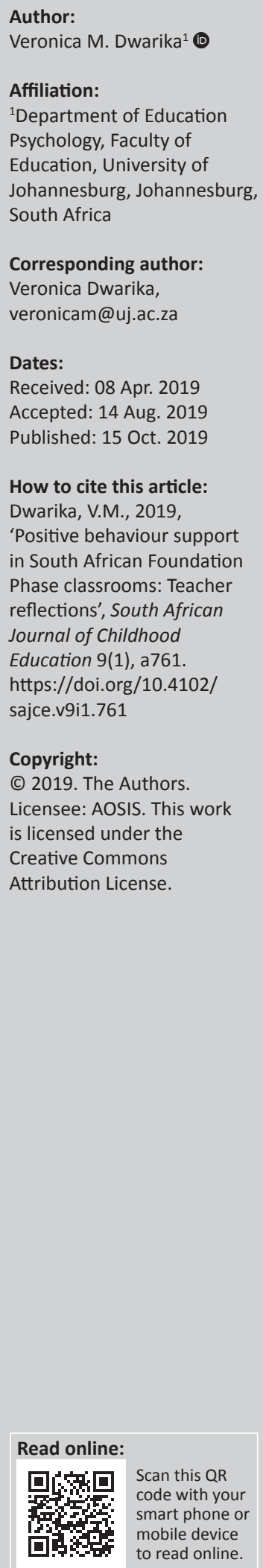

Background: The positive behaviour support (PBS) model is a model of response to address challenging behaviours of learners in schools that has proven to be effective in developed countries. Given its human rights and functional contextualism lens, the PBS model is particularly relevant to and of value within the South African context.

Aim: Since learner challenging behaviours are a key contributory factor to learner exclusion in schools, an inclusive education module on the PBS model was developed and evaluated for its effectiveness in the South African context.

Setting: The study is set within an interpretivist paradigm and utilises a generic qualitative research design.

Methods: Qualitative data were collected through module evaluations - 11 focus group interviews with 144 candidates (4th-year in-service Limpopo teachers) followed by four classroom observations and interviews with the teachers from the classroom observations.

Results: The thematic analysis revealed that participants had developed new insights about ecosystemic challenges that impact behaviour and were critically reflexive about their changed practices resulting from their participation in the inclusive education PBS model. Participants valued PBS strategies as good and useful for excellence in teaching. This evidences a pocket of success in relation to the value of the PBS model.

Conclusion: The professional development of pre-service teachers with the skills and knowledge of the PBS model for classroom practice is advocated for. Recommendations are made for further research.

Keywords: inclusion; bioecological; teacher education; positive behaviour support model; PBS; foundation phase teacher.

\section{Introduction}

Given the national and international concerns about the increase in learner challenging behaviours within schools, there is a need for comprehensive behaviour support initiatives that can assist school administrators and teachers in managing behaviour in the classrooms. In addition, given that ecological and systemic factors impact and affect learner behaviour and learner behaviour management, this study considered it imperative to view the understanding of behaviour and behaviour support from an ecosystemic perspective (Bronfenbrenner 1977, 1979, 1986, 1992; Bronfenbrenner \& Ceci 1994; Bronfenbrenner \& Morris 1998).

\section{Scientific value}

In investigating various behaviour support strategies that build inclusive classroom practices, researchers within the South African context have begun to cite the positive behaviour support (PBS) model as useful for the management of challenging behaviours in learners (Pienaar \& Raymond 2013; Western Cape Department of Education 2007). As part of a 4-year Bachelor of Education (BEd) degree at a South African university, an inclusive education (IE) module with a focus on PBS was introduced in the fourth year of the degree to in-service Limpopo teachers. The PBS model was considered to be relevant to the context of the South African classroom. The tiered approach of PBS makes it a good fit with the tiered South African Screening, Identification and Assessment (SIAS) (Department of Basic Education 2014) policy that the education department requires teachers to use in their support of learners for IE. Positive Behaviour Support takes into account the ecology of the learner, the problem behaviour and the context of the system in which behaviour support is provided (McIntosh et al. 2010). 


\section{Conceptual framework}

The conceptual framework for the ecological systems theory described in this research is based on the works of Bronfenbrenner (1977, 1979, 1986, 1992), Bronfenbrenner and Ceci (1994) and Bronfenbrenner and Morris $(1998,2006)$. The ecological theory views that human behaviour is developed and maintained through interactional processes. There is little argument that early childhood experiences are influential in shaping a child's development (Bronfenbrenner 1986). Corroborating Bronfenbrenner's theory, Perkins and Mclaughlin (2015) identified predictive risk factors, firstly, within the family, which include poor parenting skills, parental substance abuse and poor mental health, a negative or unsupportive parent-child relationship, single-parent homes, teenage pregnancies and child abuse and neglect. Secondly, the quality of environmental interactions of a child with his or her parent, teachers, peers and friends can create a potential risk or protective factors. Finally, the global environment (such as poverty, neighbourhood characteristics and home-school relationship) has an undeniable bearing. It is evident that behavioural challenges not only impact and affect the learner who is non-compliant but also impact the teacher and peers alike (Perkins \& McLaughlin 2015). Several of the predictive risk factors indicated here are prevalent in Limpopo. An understanding of behaviour and behavioural challenges, from an ecosystemic perspective within Limpopo Foundation Phase (FP) classrooms, was considered essential for this study.

\section{The ecosystemic focus of positive behaviour support}

The theoretical description of PBS that takes into account its ecological focus is 'functional contextualism', which highlights the importance of the ecology of both the specific problem behaviour as well as the environments within which behavioural support is provided (McIntosh et al. 2010). In view of this, PBS focuses on the construction of ecosystems that promote desired behaviours and minimises the development of challenging behaviours (Dunlap et al. 2009). It is therefore significantly different from previous models of behaviour modification, which relied heavily on the use of specific, sometimes aversive, intervention techniques without a clear or detailed understanding of the contextual factors underpinning the individual's behaviour (Gore et al. 2013). Within PBS practices, there is an outright rejection of methods that may involve the deliberate or conscious infliction of pain, limitation of freedom or any unnecessary constraints and restrictions on learners who present with challenging behaviours (Singer \& Wang 2009).

\section{The positive behaviour support model for inclusive classrooms}

There is a persistent need for strategies and practices that extend beyond punitive measures, which aid the development of school customs and mores that are based on non-violence and that promote positive self-discipline. The PBS model is one such approach and has been characterised by Sherrod,
Getch and Ziomek-Daigle (2009) as a proactive and preventive method to reduce challenging behaviour in schools. Positive behaviour support is based on the scientific assumption that human behaviour, while affected by a complex mix of biological, societal and learning factors, can change as a result of the actions of others in a supportive, caregiving role and is for people from all cultures, ages and levels of competence (Dunlap et al. 2009:4).

The ecological systems focus within PBS considers the school as a microsystem within the broader system of the family, community and society. The school is a locus of proximal relationships that impact and influence how the collective actions within the school contribute to how the school is characterised (OSEP 2004). From this perspective, the individual learners, teachers and parents are considered the primary context for systems change. While individuals within schools engage in behaviours, and organisations such as schools consist of a group of individuals, systems are what is needed to support the collective use of best practices by individuals within the school system (Sugai \& Horner 2009). Positive behaviour support, therefore, gives priority to the development of systems that assist in the adoption of processes and practices that fit in with and supplement the continuous efforts of school reform and development practices.

In its approach to behavioural support, the PBS model places an emphasis on values of respect for the learner, relevant and meaningful learner outcomes, dignity and selfrespect, normalisation as opposed to stigmatisation, as well as inclusion, person-centred planning and collaborative stakeholder participation (Johnston et al. 2006). Given this emphasis, the application of the PBS model is considered to be a valuable and successful alternative to the reactive and punishment-oriented approaches historically used by many schools. The use of the model also results in increased opportunities for teachers to devote more time to their teaching as opposed to managing learners' behaviour (Warren et al. 2006). McIntosh et al. (2010:10) report that the use of extensive research has been key to the success of PBS systems in reducing discipline-related problems and promoting a positive school climate with existing school resources. With increased exposure and familiarity, it can be argued that more schools will experience the benefits of using PBS strategies and become increasingly proactive in establishing school environments that are more conducive to learning (Warren et al. 2006).

Sugai and Simonsen (2012) identified the following fundamental features of PBS:

- Learner-centred outcomes that serve as the basis for selection, data collection and intervention evaluations. These outcomes are (1) academic and social, (2) individual and small group related and (3) are judged on the basis of their educational and social value and importance.

- A departure from packaged or manualised interventions towards practices that are organised to support learners 
across the school (1) school-wide, (2) within classroom and non-classroom settings and (3) with individual learner support.

- The establishment of a continuum of behaviour support practices and systems. This includes screening of the contexts within which challenging behaviours occur, ongoing monitoring of progress, team-based decisionmaking that involves all the relevant stakeholders including caregivers and professional staff, explicit monitoring of the reliability of supports that have been implemented.

- Continuous professional development for school staff, monitoring of the various phases of implementation and system-based supports (such as policies, leadership support and funding support).

- The effective, efficient and relevant use of data or information to guide decision-making. The data are used to (1) clarify the need and level of priority, (2) match the need with appropriate interventions and supports, (3) evaluate the research base in the selection of the appropriate intervention, (4) determine learner responsiveness and the outcome of the impact, (5) determine the fidelity of the intervention, (6) determine the social and ecological validity and (7) implement and adjust the intervention and support for efficiency, effectiveness and relevance. (pp. 2-3).

\section{Aims and objectives}

This study aimed to determine the effectiveness of using the PBS model in FP classrooms in the Limpopo province. To achieve this, the study sought to determine how effective and appropriate teachers found PBS in the identification and support of learners with behavioural difficulties within a selection of FP classrooms in Limpopo.

\section{Research methods and design}

This research used qualitative methods of investigation. Empirical data were gathered through course module evaluations, focus group interviews, classroom observations and interviews with teachers from the classroom observations. Data were analysed using Miles and Huberman's (1994) interactive model of thematic content analysis.

\section{The setting of the study}

The purposefully selected research participants for this study included 144 fourth-year BEd FP Limpopo in-service teachers. These teachers had undertaken the 4-year BEd degree at a South African university as part of the Department of Education's (DoE) improvement plan for its teachers.

\section{The positive behaviour support inclusive education module}

An IE module was developed using the principles of the PBS model and its applications to the school environment. The selection and sequencing of the content of the IE module were impacted by the contextual factors related to the number of weeks per hour available for the module within the university calendar. Given that teachers in Limpopo were attending the module in the fourth and final year of their BEd qualification, they had already been introduced to Bronfenbrenner's bioecological model, to the psychology of education including child development, FP classroom pedagogy and the principles of inclusion. The teachers were therefore exposed to the integration of the curriculum to facilitate the incorporation of a wide range of curricular areas, and this was considered necessary to equip teachers to apply the PBS model's classroom strategies (e.g. reflective thinking, and classroom management). The IE PBS module also drew upon previously acquired knowledge and practice as the teachers had been involved in at least two Teaching Experience practicum opportunities per year over their previous 3 years at the university. This created opportunities for the teachers to experience first-hand the cultural and contextual differences between schools in the Gauteng and Limpopo provinces.

\section{Data collection}

Empirical data were gathered through course module evaluations, focus group interviews and classroom observations. Evaluation of modules taught is a routine expectation of the university and is undertaken by students voluntarily. A module evaluation form was developed and was used to determine whether participants found the IE PBS module and its applications to the school environment to be a useful tool for the identification and support of learners with behavioural difficulties. Following the module evaluations, focus group interviews were conducted. A total of 11 focus group interviews were conducted, with each focus group having between five and seven participants. The interviews were conducted for approximately 1 hour per focus group. This was done during the time of day that was convenient to the group.

Focus group interviews are not without their challenges. Fontana and Frey (1994) identified the challenges that may arise as a result of group culture and dynamics to achieve a balance in the group interaction. In addition, there is also the reality that respondents may feel pressurised to provide what they may consider to be socially acceptable responses. To overcome this challenge, I took on the roles of a moderator and facilitator, and less that of an interviewer (Punch 2009). I sought to facilitate and moderate the group interactions by creating opportunities for each member of the group to participate, thereby facilitating individual responses of all members within the group while exploring with the group the links that emerged from the topics within the discussions. The advantage of such discussions is that it provides direct evidence about similarities and differences in participants' opinions and experiences (Mouton \& Babbie 2003). By following up on unanticipated issues and asking spontaneous questions, the group dynamics and interactions created a shaping and reshaping of the opinions as the participants reflected on, added to and shared their similar 
and/or dissimilar experiences, while providing personal insights and reasons for them (Cohen et al. 2007). This assisted in overcoming potential power relation issues as each member's participation was valued and encouraged within the group.

Furthermore, following the focus group interviews, observations were conducted in the classrooms for four volunteer participants within four schools in Limpopo. Teacher interviews following the class visits provided data specific to the classrooms within which the observations took place, thereby providing a contextual lens in relation to contributing factors to challenging behaviour in the Limpopo FP classrooms and the effectiveness of the use of PBS within the classroom context. Each classroom observation lasted for approximately 1 hour. This length of observation was considered sufficient for this particular data collection as the aim was to get a gist of the potential use of some of the PBS tools and strategies related to classroom behaviour support. Only practices that could be reasonably observed within an hour of observation were included in the observation schedule. The observation schedule was adapted from the observation tools that are available at pbis.org (https:// www.pbis.org/evaluation/evaluation-tools). The definition and operationalisation of the behaviours that count as good evidence of behaviour support practice within the observation tool were the same as those to which teachers were exposed as part of the IE PBS module.

What follows is a selection of the exemplars (examples of good practice, teacher with-it-ness exemplars) and nonexemplars (examples of poor practice, teacher with-it-ness non-exemplars). The first area of observation was classroom climate management. An example here was: the teacher makes positive and affirming statements. A non-exemplar was: the teacher seldom smiles at learners or speaks in a personal way to learners. The second area of observation was lesson planning, which included lesson delivery/presentation, lesson management and time management. An exemplar here of lesson presentation/delivery was: the teacher uses effective communication skills, organises an appropriate number and variety of instructional activities and presentation techniques. Learner engagement and learner management formed the third observation area. Non-exemplars of learner engagement included: the teacher seems unaware of the large amount of wasted time in her classroom, during which no active instruction is occurring. Either learners are not engaged in any type of learnermanaged learning activity, have not been given directions to begin an activity, are waiting for another task or are not being supervised. Classroom routines, including organisational, academic and social routines, were the fourth observation area. An exemplar here was: the teacher designs, teaches and implements a variety of organisational routines to facilitate the movement of learners, the flow of paper and instructional materials and the adherence to schedule. The final item on the observation schedule included rules and rubrics used to communicate behavioural, social and academic expectations to learners. A non-exemplar here was: there are no behavioural expectations or rubrics posted in the classroom, and there are no posted rubrics for learner behaviour or work products.

Because of the fact that observation schedules have the tendency to decontextualise what they record, it was essential to also collect information about the relevant background (Denscombe 2010). Together with the use of the observation schedule, contextual factors were recorded to collect information about relevant background matters such as class size, space available in the class for teacher movement, whether the class was a print-rich environment, etc. These observation notes enhanced the understanding of the data collected.

Following the classroom observation, individual interviews were held with the class teacher for each of the four classes. These interviews were arranged either during the lunch break or during the teacher's free period. The interviews were semi-structured and were approximately 30-40 $\mathrm{min}$ in duration. The four interviewees were the teachers of the classroom that was observed. Two interviews took place in the teachers' classrooms during a tea break and lunch break. The other two interviews were held during the teachers' free periods in the staff room.

The aim of the interviews was to provide the interviewer and interviewees with the opportunity to discuss their interpretations of the $1 \mathrm{~h}$ observed period and to express how they regarded the practical application of the PBS model from their own points of view. The interview questions were therefore built on issues covered in the observation schedule in order to increase their salience and relevance (Cohen, Manion \& Morrison 2011). The questions encouraged participants to comment on how they felt their lessons unfolded in relation to the key observed areas. The semistructured interview format ensured that the interviews remained conversational and situational. In this sense, the interviews were not merely concerned with collecting data about the lived situations, rather they afforded the opportunity for knowledge to be constructed between the participants, thereby generating the data (Cohen et al. 2007). The semistructured format further allowed for logical gaps in the data to be anticipated and closed by means of following up on an idea or topic, probing for further information or asking respondents to specify or provide examples (Kvale 1996).

\section{Data analysis}

The qualitative data (from the module evaluations, focus group interviews) were analysed using Miles and Huberman's (1994) interactive model of thematic content analysis. The data obtained from the focus group interviews were organised by the interview group. This grouping of the data from each of the focus group interviews enabled themes, patterns and similarities to be seen at a glance. While this is considered to be a useful way to summarise similar responses, it risks the 'integrity and coherence of the individual participant being lost to the collective summary' (Cohen et al. 2007:467). 
To overcome this challenge, there was a deliberate focus on individual responses, signalled by quoting responses in the discussion of the analysis. The use of direct phrases of the respondents was valuable in that they were more 'illuminative and direct than the researcher's own words' (Cohen et al. 2007:467).

With regard to the data from the observations as well as the individual interviews, each classroom observation and teacher interview was looked at as a data set before moving on to the next participant's observation and interview responses. Participants' responses given in interviews were aligned with the data from the classroom observations. Thereafter, the issues emerging from the data were drawn together across all four observations and four interviews to consider 'themes, shared responses, patterns of responses, agreement and disagreement, to compare the issues that each observation and interview raised' (Cohen et al. 2007:467). This assisted in preserving the integrity of the individual responses and enabled a whole picture of the interviews and observations across participants to take shape. Coding was then used to find themes and patterns in the data sets and across data sets (Cohen et al. 2007). Contextual realities of classroom practice as well as reported practice of PBS strategies provided an understanding of the social contexts as well as of the various discourses within the data sets, enabling a more fair-minded interpretation of the data.

Descriptive codes were used to categorise the data. The theoretical underpinning of the study, that is Bronfenbrenner's bioecological theory, inclusion matters and the literature linked to the various PBS strategies used within the behaviour support model, provided a stimulus for the overarching themes that emerged within the descriptive codes.

\section{Ethical considerations}

For this study, ethical clearance was obtained from the University of the Witwatersrand (ethical clearance number 2012ECE013). Permission was also sought and obtained from the Limpopo Department of Education. All other ethical protocols were followed, including informed consent, voluntary participation and freedom to withdraw from the study. Anonymity was guaranteed in relation to the module evaluations and classroom observations. Anonymity could however not be guaranteed in the focus group interviews as the identities of the participants within the groups were known to each other.

Within this research, I used the actual words of the participants' from the focus group interviews as well as classroom interviews as much as possible and this assisted in the promotion of descriptive as well as interpretative validity. I, however, needed to edit the language of participants for grammar but did not alter the meaning. Given that the participants' home language was not English, I did this to ensure that I did not show disfavour to the teachers' words if I put their verbatim words next to my closely edited written words.

\section{Key findings \\ Findings in relation to the theoretical framework of Bronfenbrenner's ecosystemic theory}

One of the major difficulties connected with supporting learners with behavioural challenges that have been highlighted in the literature is the way behaviour and behavioural challenges are conceptualised and understood (Ferber 2006). For teachers to have a holistic understanding of behaviour and behaviour support, it was imperative that this study provided a framework of understanding learner behaviour from within a holistic paradigm. The ecosystemic framework provided the depth and breadth of such conceptualisation. This was evidenced by $94 \%$ of respondents within the module evaluations, indicating that the ecosystemic framework of understanding behaviour and behaviour support was one of the most valuable aspects of the PBS module.

In addition, the overwhelming majority of respondents within the focus group interviews and across all of the focus groups highlighted how the development in PBS had impacted their personal reflections about their role in supporting positive behaviour among learners. A significant change reported by the majority of respondents regarded their understanding of the causes of behavioural challenges. They reported in great detail how they had become more aware of systemic factors, including their roles, which contributed to a learner's negative behaviour. The majority of respondents reported that they had previously believed the cause of the behaviour to be learner driven. They now reported having become aware that systemic factors within the learners' home as well as systemic factors within the classroom, including teaching style and classroom management, impact learner behaviour.

This increased awareness of the various ecosystemic challenges led to an in-depth understanding of learner needs in the context of the classroom and home. The majority of respondents indicated that as a result of the new information, they were obliged to engage in introspection about their behaviour in their classrooms, their teaching practices and their use of language and tone of voice, all of which have the potential to support or impede positive behaviour in learners.

Overall, the respondents indicated that their initial limited linear view of learners and learner behaviour support had changed following their participation in the IE PBS module. The linear or first-level view positions the observer (such as the teacher or other professionals) on the outside of the microsystem (school, family and individual learner), and is predisposed towards investigations about difficulties, problems and challenges that provide linear explanations when describing and understanding the individual (Amatea \& Sherrard 1994). The shortcoming of this lens is that the teacher is not considered an integral part of the system and remains an observer in the process of effecting change rather 
than a participant in the process. Following exposure to the IE PBS module and its ecosystemic theoretical underpinnings, the respondents began to consider themselves as integral to the context of support to effect behavioural changes. This shift included an understanding that there are layers or levels of interacting systems resulting in change, growth and development, and these can be physical, biological, psychological, social and cultural. The respondents of this study recognised that what happens in one system affects and is affected by other systems. This in-depth understanding is what the literature refers to as a second-level shift in conceptualising behaviour and behaviour support, which has led to respondents understanding that relationships among causes are reciprocal and multifaceted (Amatea \& Sherrard 1994).

The understanding and use of this theory resulted in the majority of respondents reporting that there was an increased understanding about the magnitude, depth and breadth that their teaching and teacher roles impacted the learners' lives in and out of the classroom. This new knowledge and holistic view of learner support about the PBS support model increased respondents' consideration of their roles within the classroom and in the broader school context, which included home-school support partnerships. The teachers were effective in situating themselves as integral to the context of understanding and supporting effective behavioural change. Within this study, it was evident that respondents had moved from understanding the individual within a psycho-medical framework to a second-level understanding which viewed learners within the various relationships and support networks of which they formed a part. Literature asserts that individuals develop through the varied activities and interactions that they engage in within their microsystems (Tudge et al. 2009).

\section{Findings concerning the inclusion of learners with behavioural challenges}

As is the case elsewhere, within the South African context, issues of inclusion and inclusive practices continue to be an essential aspect of local, national and international discussion about how best to respond to learners who experience difficulties in school (Engelbrecht et al. 1999). Embedded in the discussion, research and inclusive practices debate is the call to reduce the number of learners excluded from school for disciplinary reasons (Evans, Harden \& Thomas 2004). The imperative to support learners who present with behavioural challenges has emerged in this study as a core outcome. Respondents within this study previously engaged in a variety of exclusionary practices (learners were 'just left outside', were 'shouted at', 'beaten', etc.), and following their participation in the IE PBS inclusion module, they reported that they now reflect on, assess and develop values and beliefs as well as instructional teaching and assessment practices that support the inclusion of learners who present with challenging behaviours. Such deep teacher reflection and a move towards inclusionary practices and action are supported by the literature as the key to educational change (Walton 2011).
The majority of respondents within the study reported using various PBS strategies. Respondents reflected on how their attitudes to teaching and learners had become more supportive and less exclusionary. This result supports the literature that states that 'what teachers think, what teachers believe and what teachers do at the level of the classroom ultimately shapes the learning that young people get' (Hargreaves 1994:1). While earlier literature about PBS application was absent in the South African context, there is now information that assists in considering this model of behaviour support as useful and relevant to a different context.

\section{Factors teachers attributed to learner challenging behaviours in their classroom}

Within the theoretical framework of Bronfenbrenner's ecosystemic theory, behaviour and behaviour support can only be fully understood taking into account the personenvironment context that represents the entirety of relationships and interactions among individuals and their environments. The findings of this study were that the factors perceived by respondents to contribute to learner challenging behaviours in Limpopo FP classrooms were those negative factors within the home, school and immediate communities. It was these proximal interactions that are highlighted in the relevant literature, which were found to be relevant in this study as well. These included the interaction between the parent and child, the teacher and learner as well as the learner and other learners (Bronfenbrenner 2006).

The three main microsystem factors contributing to learner challenging behaviour were found to be the following:

- Within the home microsystem - issues of parental violence, abuse and neglect were reported as the main contributors to learner challenging behaviour. Learners' modelling of this learned behaviour were deemed to cause conflict and behavioural challenges within the classrooms.

- Within the home and wider community mesosystem issues linked to child-headed families and poverty were considered the main contributing factors to learner challenging behaviour. The survival needs of the learners were considered by respondents to be the overriding factor that hindered them from full participation in the class. Attention difficulties because of beleaguered concern for personal and sibling welfare reportedly dominated learners' thoughts, leaving little chance for active participation in lessons. Learner withdrawal, truancy and extended periods of absenteeism and dropping out of school were the results.

- Within the school and classroom microsystem - here, issues that were considered to be major factors that contributed to learner challenging behaviour - were teacher frustration and teacher apathy. Closely linked to these were teachers' inadequate education and professional development in behaviour support strategies and their widespread use of corporal punishment. Classroom pedagogical strategies were also a significant contributor where respondents stated that they did not 
plan their lessons well, nor did they cater to the differentiated needs of learners during their lesson planning and presentation. These factors were mostly interrelated and impeded the building of positive and healthy relationships between the learners and the teachers.

The shift reported by respondents, who initially viewed themselves as outside and apart from the systems that impact learner behavioural challenges, involved them seeing themselves as integral contributors to behaviour challenges, and also as part of the possible solution to the support of learners with behavioural challenges. Reported reflexive introspection by the respondents led them to consider themselves as agents of change within the system and as capable of offering protective support concerning behavioural challenges when applying PBS strategies of behavioural support in the classroom.

\section{Teachers' perceptions of their abilities to manage challenging behaviours}

The respondents considered that before they were exposed to the IE PBS module, their ability to manage behavioural challenges was inadequate. They lamented their inadequate initial teacher education and the lack of professional development courses in behaviour support and behaviour management. Their concern about the inadequacies in their approach was indeed legitimate and is supported by previous findings (Green et al. 2011).

Following their participation in the IE PBS module, the majority of respondents felt better-equipped to deal with learner challenging behaviours in the classroom. The PBS strategies found by the majority of respondents to be most relevant to the management of behavioural challenges are summarised below:

- Classroom rules: The use of classroom rules that were negotiated and co-constructed with learners was found by respondents to be a useful behaviour support tool. During the classroom observations, all four of the classrooms had the classroom rules posted in clear view of the learners. In one classroom, the teacher referred to the rules during the lesson to remind learners of turntaking as part of the social support of each other during activities. Learners were able to follow-through with the rule with ease and confidence. In the other three classrooms, learners seemed to have internalised the rules and were able to practise them within the lesson without much need for teacher prompting.

- The formulation and practical application of classroom rules were not without its challenges. Challenges were reported by respondents about teacher-learner collaboration during the formulation of the rules, given that active learner participation was a strategy that was not previously well used. Respondents, however, were eager to change this and work towards healthier engagement and building of learner trust which would result in communication by learners towards the teacher being less restrained. This was seen in the classroom observations where the practice of the rules was followed through with ease, and teachers supported learners with praise for their follow-through.

- Furthermore, challenges in relation to the systemic challenges of home-school collaboration observed by respondents were the sustainability and impact of classroom and school rules. One teacher in the classroom interviews attributed a lack of sustainability to the inconsistency between what is allowed to happen at home and what is allowed to happen at school. It was evident that the respondents in the focus group interviews as well as within the classroom interviews were acutely aware that early childhood experiences were influential in shaping a child's development (Bronfenbrenner 2006).

- Praise and rewards and tokens: While the majority of respondents reported that the use of praise was not used extensively before their exposure to the PBS model, the use of praise and rewards was considered by the majority of respondents as a useful tool to support learner behaviour in the classrooms. The impact of praise on building learner self-esteem and confidence was considered useful. As is suggested by supporting studies (Byron \& Khazanchi 2012), the majority of respondents also found that the use of these motivating supports assisted in building positive relationships between the learners and the teachers. Respondents found this PBS strategy invaluable in recognising and rewarding desirable learner behavioural outcomes.

- Home-school collaborations: The majority of respondents found that home-school partnerships were useful for healthy relationships between parent/caregivers and teachers. They were also considered vital to ensure a united base of support for the learners that facilitated joint parent-teacher efforts related to learner behavioural support. Studies by Westergard (2013) revealed the benefits of parental partnerships and collaborations. This was further confirmed in this study. The importance of the role of parents concerning home-school partnerships is also recognised in legislation and policies including the South African Schools Act (1996) and Education White Paper 6 (DoE 2001).

- While the value of the PBS strategy of building partnerships was widely recognised, the respondents also recognised challenges linked to building effective and supportive partnerships. These findings were confirmed to be the same as others highlighted within the literature (Westergard 2013). Other challenges reported were linked to parents' work pressures, parental disillusionment, parental illiteracy and parental fear of judgement and rejection. Despite the challenges reported by respondents in developing and promoting positive home-school partnerships, the importance of seeking ways of promoting partnerships was considered to outweigh the risks. The respondents felt that they had a responsibility towards the learners to go the extra mile in making an effort to increase home-school cooperation. This included a recognition of 
the value of parents having increased opportunities to have their voices heard within the school community. This finding concurs with those of other studies which emphasise that for the development of collaborative partnerships, school management and teachers need to be proactive in fostering trust and respect in the building of effective communication with parents (Westergard 2013).

- Purposeful lesson planning: Respondents reported that the strategy of curriculum differentiation created opportunities for careful planning of lessons and lesson task activities. Furthermore, the respondents reflected on their increased awareness of the need to research the content of the lesson and to ensure that the level that the lesson is pitched at is not below or above the learners' levels of comprehension. This increased awareness would have developed over their 4 years at the university as it related to aspects of their TE activities for the degree. It had assisted respondents in planning lessons more effectively such that there was a more appropriate use of the time spent on the lessons and the related activities. The reported effective use of the PBS strategy of differentiation was confirmed during the school visit within the Limpopo province. It was evident in three of the lessons observed that the teachers took care in planning their lessons and that they used selective differentiated activities including workbook and worksheet activities and group work activities that were appropriate to learner needs. Learning objectives were clearly defined and well-articulated in the lesson plan. One of the teachers expressed that the lesson plan format from the university afforded her the best organisational planning tool to date. Learners were found to participate and enjoy the tasks set out for them. The findings in support of the strategy of curriculum differentiation correspond with those of Wuim and Louw (2015), who state that differentiation provides access to learning, thereby supporting learners' experience of academic success.

The value of PBS found by the participants in this study is congruent with international findings of the value of the PBS model of behaviour support (McIntosh et al. 2010). The emphasis is on the core values of 'respect for the individual, meaningful outcomes, social validation, dignity, normalisation, inclusion, person-centred planning, selfdetermination, and stakeholder participation' (Johnston et al. 2006:54). The application of the PBS model within this study was a valuable and successful alternative to the 'reactive, punishment-oriented approaches historically used by many schools' (Johnston et al. 2006:54).

\section{How effective did the Limpopo FP teachers find the positive behaviour support model for classroom practice?}

An overall evaluation of the Inclusion module that was taught, as well as teachers' responses during the focus group interviews and classroom observations, provided sufficient data to confirm that the Limpopo FP teachers indeed found the PBS model and effective and appropriate tool that could be used in support of learners who present with behavioural challenges in their classrooms. All respondents indicated on the module evaluation forms that they would use the strategies in their classrooms to assist them in support of learners with behavioural challenges. The majority of respondents (94\%) indicated that they had found the following aspects of the PBS module most valuable:

- understanding the child within the context of the home, school and environment (ecosystemic framework)

- the differences between discipline and punishment

- alternatives to corporal punishment which included classroom-wide support of how to formulate and integrate classroom rules, differentiated teaching, teacher preparedness and functional behavioural assessments

- positive reinforcement strategies including the use of praise, token economy and rewards

- strategies for building school and parent/family partnerships.

There was strong support for the model, particularly once an understanding of the various factors that contributed to behavioural challenges had been established. While previously learners were believed to be just naughty, the ecosystemic understanding of how the learners' home, school and family contexts impact his or her behaviour was reported to be valuable. The participants reported that the ecosystemic view opened up the channel for them to consider their part in the various systems within the school context that led to challenging learner behaviour. Such a realisation reportedly allowed the respondents to be reflexive about their role within the system of support and make the necessary classroom practice and attitude adjustments. The Limpopo FP teachers unanimously reported a better and deeper understanding of the contributory contextual factors that impact challenging behaviour in the classroom.

All respondents without exception found that where previously they felt inadequately prepared to manage behavioural challenges, the PBS strategies they were taught were very valuable in addressing behavioural challenges and were a welcome support for their classroom practices. Common behaviour management practices that respondents admitted to having been using were highlighted within the focus group interviews as being inappropriate and ineffective. These included the use of corporal punishment, negative attitudes by teachers towards learners and towards teaching, as well as prevalent practices of favouritism, victimisation and labelling of learners. These same behaviour management strategies, together with the majority of respondents' reported lack of knowledge of appropriate teaching strategies, challenging contextual factors of overcrowded classrooms and challenging systemic factors related to home-school partnerships, were also considered by the majority of respondents as factors that contributed to challenging behaviour in the class. 


\section{Positive behaviour support strategies within the observed classrooms}

Overall, the classroom observations revealed a general use and application of the following PBS principles: positive classroom and climate management, relevant lesson and time management, organised lesson designs, meaningful lesson presentations, meaningful use of organisational rules, appropriate management of learner conflict/disruptions, as well as appropriate use of social rules and routines.

The PBS strategies that were reported by the teachers to have been most effective included the use of praise/rewards/ tokens. Efforts towards greater parent-teacher collaboration were also highlighted, together with the use of classroom rules. This can be observed in the teachers' comments below. In addition, the appropriate use of silence as well as positive regard for the learners and the appropriate use of affection were also significant strategies that were reported to be assisting in getting learners to attend as well as build positive relationships with the teacher. An example of the effectiveness found in the use of silence in the classroom is reflected in the following excerpt:

'I used this thing of just being quiet, I never thought it will work. I just go in, see them making a noise and I just say, stand up, fold your arms, and close your mouth. And you can see they are just surprised, I am talking soft not shouting and soon they all become surprised and just do it, I just say fold your arms, close your mouth, and yes this thing is working! One by one they become quiet. We are used to shouting and saying KEEP QUIET!!! But they don't stop. Hey, but this thing it works (laughing). It was the first time I saw being soft can calm children down.' (School 1, teacher 1, female)

Positive regard, affection and emotional support of learners were also reported to be strong contributing factors to building learners' self-esteem and sense of belonging in the classroom. This, in turn, reportedly encouraged positive behaviour practices from the learners. The responses below highlight the moving stories that one teacher told of the value of emotional connectedness within the classroom:

'Just to give them (learners) hugs or a kiss on the head, just to praise them. ...you see it is working and they feel comfortable and share what is happening.' (School 1, teacher 2, female)

'That child from Zimbabwe told me he wants me to be his mum. I asked him why, he said he has never been hugged before. So you see, just showing some love is a very big thing for that child.' (School 1, teacher 2, female)

Given the value that respondents found in the use of the PBS model support strategies, there was widespread advocacy for other teachers in the province also to undergo such professional development. The issue of needing more time to practise the strategies was raised by a large number of respondents, together with the need for continued professional development in the area of behaviour support for all teachers in the Limpopo province. The overall feeling of participants was that such knowledge needed to be shared for the broader support of learners within their schools and learning communities.

\section{Implications for professional development programmes}

The teachers considered that the PBS strategies were good and useful for excellence in teaching, and the limitation was that only a few teachers had been exposed to it. The impact of the respondents' strategies of behaviour support was creating awareness among other teachers that there was a different, better way to support learners who present with behavioural challenges. The lack of opportunity for these strategies to be shared with their colleagues was highlighted as a challenge. All respondents reported that it was imperative for teachers within their schools to have an opportunity to learn the principles and practical applications of the PBS model and thereby learn healthier support mechanisms by which challenging learner behaviours could be addressed. One poignant reflection was when one teacher expressed: '...it is a waste for us to be the excellent teachers alone'. The idea of increased exposure and familiarity with the PBS model is strongly supported by literature as having the advantage of more teachers within schools and more schools within districts experiencing the benefits of using PBS strategies to 'proactively establish school environments [to be] more conducive to learning' (Warren et al. 2006:196). In order to ensure that IE is embraced and pursued by all teachers, there continues to be a need for professional development and support (Ntombela \& Raymond 2013).

Shulman (1986) explains that teacher education should function to teach prospective teachers how to use ideas and theories in their classroom practice and should also help them to investigate and discover how those ideas and theories in effect manage those who attempt to engage them. The imperative that teacher education programmes incorporate effective behaviour support strategies together with general pedagogical development and specific classroom behaviour support management techniques has been proven valuable in the findings of this research. The findings provide a compelling argument that the ideas and theoretical underpinnings of the PBS model should form part of the support strategies that prospective teachers are exposed to as part of their pre-service education.

\section{Limitations of the study}

This research deliberately focused on Limpopo FP teachers during their teacher education degree at the university. The PBS model was evaluated for the effectiveness of its use within the specific context of Limpopo. The findings that emerged from the study provide rich data to support a meaningful understanding of the value of PBS that has been found within a specific context. It is however accepted that the specific context would limit the generalisability of the findings to other South African contexts. 
The PBS model is a model used predominately in overseas countries as a school-wide model of support. For this study, the model was adapted to focus only on the classroom PBS strategies. The use of the model as a complete three-tiered approach was therefore not investigated. Despite having to practise the PBS strategies in isolation from their colleagues, the respondents nevertheless willingly tried out the PBS model of support. This can be considered as a sign of the perceived value of the PBS model and the respondents' adaptability to use different forms of learner support in their classrooms.

A further limitation evolved out of one of the findings of the study. The majority of respondents expressed strongly that all FP teachers within the Limpopo province should have the opportunity to participate in professional development on behaviour support and the PBS model. This urgent call by the respondents, while accepted as legitimate, was not possible to be addressed within the scope of this research. The respondents commented on the interest shown by their colleagues at their schools concerning the good practices they saw being implemented. The majority of respondents expressed the concern that there was little opportunity for them to share their expertise with others, given the busy schedules of all the teachers and the heavy workloads.

\section{Implications for further research on positive behaviour support in the South African context}

While this study is possibly the first to provide information about the value of PBS within the South African context, and specifically within the province of Limpopo, there are extensive opportunities to conduct further research on the model within the rest of the country. Literature suggests that in South Africa teachers may find it harder to adopt new strategies for various contextual reasons. Contextual factors that may impede teacher uptake include teachers' difficulties with lack of appropriate resources, poor learner engagement and teachers' own poor teacher education as a result of Bantu Education (Chrisholm 2003). Further studies in various other South African contexts would, therefore, provide invaluable information with regard to possible generalisability of the value of PBS support in this country's context.

Although the findings of this study indicate a pocket of success in relation to the value of PBS, further studies to explore the value of long-term school-based behaviour support with PBS interventions can provide data in relation to whether the model achieves success in the reduction of behavioural challenges within schools and classrooms in different contextual settings. Various national and international studies argue for the effectiveness of intervention programmes that include coaching and followup programmes. The duration of such programmes generates opportunities for collaborations, group inquiry into practice and individual reflections (Brodie 2008). Research into the long-term use of PBS support programmes in collaboration with school-based support teams across various districts in different provinces of the country may provide further information concerning teacher uptake of intervention and support programmes in the area of behaviour support.

\section{Conclusion}

In light of the fact that at the time of this study I did not find much documented research regarding the use of PBS within the South African context, the findings of this study suggest that it is the first of its kind. The study offers an indication of the value and effectiveness of PBS within South Africa. The findings of this study reveal that the Limpopo FP teachers indeed found that the PBS model was a practical and useful tool for the understanding and support of learners who present with behavioural challenges in their classrooms. Overall, the research findings provided evidence to support the effectiveness of the PBS model for Limpopo FP classrooms and, in doing so, have been successful in providing useful information about the use of the PBS model in the South African context. The PBS model was found to be valuable and useful in helping the Limpopo FP teachers better understand and better manage behavioural challenges in their classrooms. The opportunities for exploration of the PBS model within higher education courses for teacher education are possible given the value the FP teachers found in the IE PBS module taught. This, I would argue, will equip teachers with the skills and knowledge to support positive behaviour in the classroom.

\section{Acknowledgements}

This research has been based on the author's PhD thesis submitted to the University of the Witwatersrand.

\section{Competing interests}

The author declares that she has no financial or personal relationships that may have inappropriately influenced her in writing this article.

\section{Authors' contributions}

V.M.D. is the sole author of this article.

\section{Funding information}

The research reported in this article was supported by the European Union Primary Education Policy Support Programme (EU PPSP).

\section{Data availability statement}

New data were created or analysed in this study.

\section{Disclaimer}

The views and opinions expressed in this article are those of the author's and not an official position of the institution or funder. 


\section{References}

Amatea, E.S. \& Sherrard, P.A.D., 1994, 'The ecosystemic view: A choice of lenses', Journal of Mental Health Counseling 16(1), 6-16.

Brodie, K., 2008, 'Describing teacher change: Interactions between teacher moves and learner contributions', in P. Valero \& K. Yasukawa (eds.), Proceedings of the fifth international mathematics education and society conference, Department of
the University of Algarve, Albufeira, Portugal, February 16-21, 2008, pp. 31-50.

Bronfenbrenner, U., 1977, 'Towards an experimental ecology of human development', American Psychologist 32(7), 513-531. https://doi.org/10.1037/0003-066X.32.7.513

Bronfenbrenner, U., 1979, The ecology of human development, Harvard University Press, Cambridge.

Bronfenbrenner, U., 1986, 'Ecology of the family as a context for human development: Research perspectives', Developmental Psychology 22(6), 723-742. https://doi. org/10.1037/0012-1649.22.6.723

Bronfenbrenner, U., 1992, 'Ecological systems theory', in R. Vasta (ed.), Six theories of child development: Revised formulations and new trends, pp. 187-249, Jessica Kingsley, London.

Bronfenbrenner, U. \& Ceci, S.J., 1994, 'Nature-nurture reconceptualised in developmental perspective: A biological model', Psychological Review 101(4), 568-586. https://doi.org/10.1037/0033-295X.101.4.568

Bronfenbrenner, U. \& Morris, P.A., 1998, 'The ecology of developmental processes', in R.M. Lerner (ed.), Handbook of child psychology. Volume 1: Theoretical models of human development, pp. 993-1027, John Wiley \& Sons, New York.

Bronfenbrenner, U. \& Morris, P.A., 2006, 'The bioecological model of human development', in W. Damon \& R.M. Lerner (eds.), Handbook of child psychology: Theoretical models of human development, pp. 793-828, Wiley, New York.

Byron, K. \& Khazanchi, S., 2012, 'Rewards and creative performance: A meta-analytic test of theoretically derived hypotheses', American Psychological Association 138(4), 809-830. https://doi.org/10.1037/a0027652

Chrisholm, L., 2003, 'The state of curriculum reform in South Africa: The issue of Curriculum 2005', in A. Habib, R, Southall \& J. Daniel (eds.), State of the nation, pp. 24-37, HSRC, Pretoria.

Cohen, L., Manion, L. \& Morrison, K., 2011, Research methods in education, Routledge London.

Cohen, L., Manion, L., Morrison, K. \& Morrison, K.R.B., 2007, Research methods in education, Routledge, New York.

Denscombe, M., 2010, The good research guide: For small scale social research projects, Open University Press, London.

Department of Basic Education, 2014, Draft policy on screening, identification, assessment and support, Government Printer, Pretoria.

Department of Education (DoE), 2001, Education White Paper 6: Special need education: Building an inclusive education and training system, Government Printer, Pretoria.

Dunlap, G., Sailor, W., Horner, R. \& Sugai, G., 2009, 'Overview and history of positive behavior support', in W. Sailor, G. Dunlap, G. Sugai \& R. Horner (eds.), Handbook of positive behavior support, pp. 3-16, Springer Science \& Business Media LLC, New York.

Engelbrecht, P., Green, L., Naicker, S. \& Engelbrecht, L. (eds.), 1999, Inclusive education in action in South Africa, Van Schaik Publishers, Pretoria.

Evans, J., Harden, A. \& Thomas, J., 2004, 'What are effective strategies to support pupils with emotional and behavioral difficulties (EBD) in mainstream and primary schools? Findings from a systematic review of research', Journal of Research schools? Findings from a systematic review of research', Journal of Research
in Special Educational Needs 4(1), 2-16. https://doi.org/10.1111/J.1471-3802. in Special Educa

Ferber, M.P., 2006, 'Critical realism and religion: Objectivity and the insider/outside problem', Annals of the Association of American Geographer 96(1), 176-181.

Fontana, A. \& Frey, J.H., 1994, 'Interviewing the art of science', in N. Denzin \& Y. Lincoln (eds.), Handbook of qualitative research, pp. 361-376, Sage, Thousand Oaks, CA.

Gore, N.J., McGill, P., Toogood, S., Allen, D., Hughes, C.J., Baker, P. et al., 2013 , 'Definition and scope for positive behavioral support', International Journal of Positive Behavioral Support 3(2), 14-23.

Green, W., Parker, D., Deacon, R. \& Hall, G., 2011, 'Foundation phase teacher provision by public higher education institutions in South Africa', South African Journal of Childhood Education 1(1), 109-122. https://doi.org/10.4102/sajce.v1i1.80
Hargreaves, A., 1994, Changing teachers, changing times, Redwood Books, London.

Johnston, J.M., Foxx, R.M., Jacobson, J.W., Green, G. \& Mulick, J.A., 2006, 'Positive behavior support and applied behavior analysis', Behavior Analyst 29(1), 51. https://doi.org/10.1007/BF03392117

Kvale, S., 1996, Interviews: An introduction to qualitative research interviewing, Sage, Thousand Oaks, CA.

McIntosh, K., Filter, K.J., Bennet, J.L., Ryan, C. \& Sugai, G., 2010, 'Principles of sustainable prevention: Designing scale-up of school-wide positive behavior support to promote durable systems', Psychology in the Schools 47(1), 5-20. https://doi.org/10.1002/ pits. 20448

Miles, M.B. \& Huberman, A.M., 1994, Qualitative data analysis. An expanded sourcebook, Sage Publications, London.

Mouton, J., \& Babbie, E., 2001, The practice of social research, Cape Town: Wadsworth Publishing Company.

Ntombela, S. \& Raymond, E., 2013, 'Inclusive education in South Africa and globally', in C.F. Pienaar \& E.B. Raymond (eds.), Making inclusive education work in classrooms, pp. 2-17, Pearson Education South Africa, Cape Town.

OSEP Center on Positive Behavioral Interventions and Supports, 2004, School-wide positive behavior support implementers' blueprint and self-assessment, University of Oregon, Oregon.

Perkins, H.R. \& McLaughlin, T.F., 2015, 'Classroom intervention for elementary school children with EBD: A brief review', International Journal of Applied Research 1(4), 24-29.

Pienaar, C.F. \& Raymond, E.B. (eds.), 2013, Making inclusive education work in classrooms, Pearson Education South Africa, Cape Town.

Punch, K.F., 2009, Introduction to research methods in education, Sage, London.

Sherrod, M.D., Getch, Y.Q. \& Ziomek-Daigle, J., 2009, 'The impact of positive behavio support to decrease discipline referrals with elementary students', Professional School Counseling 12(6), 421-427. https://doi.org/10.5330/PSC.n.2010-12.421

Shulman, L.S., 1986, 'Those who understand: Knowledge growth in teaching', EducationalResearcher15(2), 4-14.https://doi.org/10.3102/0013189X015002004

Singer, G.H.S. \& Wang, M., 2009, 'The intellectual roots of positive behavior support and their implications for its development', in W. Sailor, G. Dunlap, G. Sugai \& R. Horner (eds.), Handbook of positive behavior support, pp. 17-48, Springer Science \& Business Media LLC, Germany.

Sugai, G. \& Horner, R.H., 2009, 'Defining and describing school-wide positive behavior support', in W. Sailor, G. Dunlap, G. Sugai \& R. Horner (eds.), Handbook of positive behavior support, pp. 307-326, Springer Science \& Business Media LLC, US.

Sugai, G. \& Horner, R.H., 2009, 'Responsiveness-to-intervention and school-wide positive behavior supports: Integration of multi-tiered approaches', Exceptionality 17(4), 223-237. https://doi.org/10.1080/09362830903235375

Sugai, G., Horner, R. \& Algozinne, B., 2011, Reducing the effectiveness of bullying behavior in schools, OSEP Center on Positive Behavioral Interventions and Supports, viewed 23 Nov 2018, from https://www.pbis.org/common/cms/files/ pbisresources/PBIS_Bullying_Behavior_Apr19_2011.pdf.

Sugai, G. \& Simonsen, B., 2012, Positive behavioral interventions and supports: History, defining features, and misconceptions, Center for PBIS \& Center for Positive Behavioral Interventions and Supports, University of Connecticut, viewed 23 Nov 2018, from http://idahotc.com/Portals/6/Docs/2015/Tier_1/articles/ 23 Nov 2018, from http://idahotc.com/P
PBIS history.features.misconceptions.pdf.

Tudge, J.H.R., Mokrova, I., Hatfield, B.E. \& Karnick, R.B., 2009, 'Uses and misuses of Bronfenbrenner's bioecological theory of human development', Journal of Family Theory and Review 1(4), 198-210. https://doi.org/10.1111/j.1756-2589.2009. 00026.x

Walton, E., 2011, 'Getting inclusion right in South Africa', Intervention in School and Clinic 46(4), 240-245. https://doi.org/10.1177/1053451210389033

Warren, J.S., Bohanon-Edmonson, H.M., Turnbull, A.P., Sailor, W., Wickham, D., Griggs, S. et al., 2006, 'School-wide positive behavior support: Addressing behavior problems that impede student learning', Educational Psychology 18(2), 187-198. https://doi. org/10.1007/s10648-006-9008-1

Westergard, E., 2013, 'Teacher competencies and parental cooperation', Internationa Journal About Parents in Education 7(2), 91-99.

Wuim, A. \& Louw, B., 2015, 'The South African national school curriculum: Implications for collaboration between teachers and speech-language therapists working in schools', South African Journal of Childhood Education 5(1), 19-41. https://doi org/10.4102/sajce.v5i1.348 